\title{
ENCONTRO DE DUAS ROTAS: Uma breve análise sobre o fluxo de deslocamentos forçados congoleses e a rede institucional da Cáritas Rio
}

MEETING OF TWO ROUTES: A brief analysis of the flow of Congolese displacement and the institutional network of Caritas Rio

Joanna Rocha Muniz ${ }^{1}$

\section{RESUMO}

Este artigo descreve o encontro de dois fluxos transnacionais distintos: a chegada de congoleses que solicitam refúgio ao Brasil e os mecanismos da ajuda humanitária que incidem sobre instituições que trabalham voltadas para esta população. O ponto de encontro ao qual esta análise descreve é a rede que se tece através da Cáritas Rio para o atendimento à refugiados, buscando esboçar as diferentes pautas que a atravessam e o modo como elas se efetivam na prática. Além disso, este artigo faz uma breve retrospectiva histórica da República Democrática do Congo, com o intuito de compreender o contexto que permeia os deslocamentos.

Palavras-chave: refugiados; Cáritas Rio; ajuda humanitária; deslocamentos.

\section{ABSTRACT}

The present article intends to describe the meeting of two distinct transnational flows: the arrival of Congolese refugees in Brazil and the mechanisms of humanitarian aid on institutions working for this population. The meeting point of this analysis describes the network that is formed through Caritas Rio to assist refugees, trying to show the different patterns that cross it and how they are implemented in practice. Among other questions, this article gives a brief historical retrospective of the Democratic Republic of Congo, to understand the context that permeates the displacements.

Key-words: refugees; Cáritas Rio; humanitarian aid; displacements.

\footnotetext{
${ }^{1}$ Mestra em Sociologia pelo Programa de Pós-graduação de Sociologia e Antropologia da Universidade Federal do Rio de Janeiro (UFRJ). E-mail: joanna.muniz@ hotmail.com
} 


\section{Introdução}

Atualmente, grandes fluxos migratórios estão sendo noticiados e agrupados no perímetro do refúgio pela mídia, Estados-nações, agências multilaterais e pessoas. Os números que se propõem relatar esta realidade são realmente alarmantes. Em 2013, o Alto Comissariado das Nações Unidas para Refugiados (ACNUR) anunciou que os deslocamentos forçados afetavam 51,2 milhões $^{2}$ de pessoas, número mais alto desde a Segunda Guerra Mundial. De acordo com o relatório anual Global Trends do ACNUR - formado com base em dados de governos, agências parceiras e do próprio ACNUR -, em 2015 há um total de 65,3 milhões ${ }^{3}$ de pessoas deslocadas por guerras e conflitos - um aumento de quase $10 \%$ se comparado com o total de 2014. Definitivamente, estes dados são alarmantes por anunciar a possibilidade de novas concepções de povos, etnias e nacionalidades, e trazem consigo reflexões acerca de fronteiras, distancias, globalização e modelos de desenvolvimento.

O Brasil tem se tornado rota de fuga para aqueles que buscam fugir de guerras, conflitos e são vítimas de perseguição. Sua legislação de refúgio é considerada moderna (Lei 9.474/97) por adotar um conceito ampliado para reconhecimento de refugiados, além das situações previstas nas convenções internacionais. O Comitê Nacional para Refugiados (CONARE) é um órgão multiministerial fruto desta lei, no qual participam o governo, a sociedade civil e a ONU. De acordo com o relatório produzido em 2016 (com recorte até abril), as solicitações de refúgio cresceram $2.868 \%$ nos últimos cinco anos no Brasil, passando de 966, em 2010, para 28.670, em 2015. Grande parte dos refugiados vivem em cidades e a maioria está concentrada em grades centros urbanos, podendo obter documentos, trabalhar, estudar e exercer os mesmos direitos civis que qualquer cidadão estrangeiro em situação regular no Brasil. Os sírios formam a maior comunidade de refugiados reconhecidos, seguidos por angolanos, colombianos, congoleses e palestinos.

Sobre a realidade exposta, este artigo procura compreender o emaranhado institucional que se estabelece para o acolhimento de refugiados congoleses no país. O ponto de análise se estabelece na Cáritas Arquidiocesana do Rio de Janeiro, instituição que é parte da Cáritas Internationalis, parceira do ACNUR e membro do CONARE, representando a sociedade civil com direito a voz e voto nas decisões do comitê. No Rio de Janeiro, a nacionalidade mais

\footnotetext{
${ }^{2}$ UNHCR, Global Trends 2013: Forced Displacement in 2013.

${ }^{3}$ UNHCR, Global Trends 2015: Forced Displacement in 2015.
} 
expressiva de refugiados é de origem da República Democrática do Congo (RDC), perfazendo cerca de $40 \%$ dos refugiados que chegaram a entidade em 2015. Para realizar o acolhimento a estes refugiados, a instituição se associa e conta com o apoio de diversas outras entidades, públicas e privadas, com o intuito de ampliar seus esforços. Nem sempre a visibilidade deste emaranhado é possível e documentos não estão em total igualdade com a prática, fato este que dificulta o desmembramento institucional e a ligação entre pontos de interesse.

Para este trabalho, busco realizar um esforço inicial em sistematizar dois pontos de circularidade. Primeiro, pretendo compreender o fluxo de congoleses que se deslocam forçosamente de seu país para o Brasil, através de pesquisa bibliográfica e retrospectiva histórica, além dos relatos que obtive ao longo de minha pesquisa de campo. Posteriormente, me debruço sobre a análise dos canais institucionais que até então se tornaram visíveis no apoio a esta causa no país. Se no primeiro ponto a análise terá como enfoque a circularidade de pessoas, no segundo momento os esforços recairão sobre a circularidade institucional de valor, conhecimento e gramática. Ao fim, pretendo realizar um breve ensaio sobre o encontro destas duas circularidades que possuem recortes diferentes, mas incidem sobre uma mesma realidade. Acredito que estes dois pontos não podem ser enxergados de forma separada e a análise de seu encontro pode auxiliar na compreensão de como vem sendo realizados os esforços globais para atuar sobre esta realidade crescente.

\section{Dois pontos}

A largada destes dois pontos se dá, de um lado, pelo fluxo de migração forçada de congoleses para o Brasil, em que estes saem da sua terra natal, fugindo de guerras, perseguições e violação dos direitos humanos, com o intuito de se fixarem no Brasil; e, por outro lado, a movimentação de instituições e agências multilaterais que se mobilizam por esta causa, formando emaranhados institucionais ${ }^{4}$ e estabelecendo conexões. Com isso em mente, acredito que estes são dois pontos de partida que se encontram em um terceiro ponto específico: o acolhimento da Cáritas Arquidiocesana do Rio de Janeiro aos refugiados congoleses. É através deste encontro que busco desmembrar os dois fluxos que colidem, no qual estes rompem barreiras temporais e espaciais.

\footnotetext{
${ }^{4}$ VIANNA, Anna Catarina Morawska. 2010. "Os Enleios da Tarrafa: etnografia de uma parceria transnacional entre ONGs através de emaranhados institucionais de combate à pobreza". Tese de Doutorado. São Paulo: Faculdade de Filosofia, Letras e Ciências Humanas/USP.
} 
É perceptível que estes dois objetos são distintos: por um lado se fala de instituições e por outro lado de pessoas. Isto sem citar a assimetria de facilidade de deslocamento, em que de um lado as fronteiras se abrem para os canais institucionais e, de outro lado, é preciso violá-la, romper com as cercas pré-estabelecidas. Entretanto, esta disparidade compõe o cenário mundial e faz parte dos diversos fluxos que se estabelecem atualmente, conectando diferentes entidades, pessoas e objetos. A antropóloga Anna Catarina Morawska Vianna (2010) lança luz sobre a possibilidade de compreender estas conexões através de um tipo de prática etnográfica explicada por George Marcus que toma como preocupação conexões cada vez mais evidentes dentro daquilo que é concebido como "sistema mundial", em que este não deve ser tratado apenas como um pano de fundo, mero contexto de realidade (VIANNA, 2010. p. 70), mas como primordial a compreensão do todo.

Como mostra o autor Ulf Hannerz a abordagem sobre "fluxos" é ampla e diversas disciplinas se debruçam sobre ela, o que torna este termo transdisciplinar fazendo referência a coisas que "não permanecem no seu lugar, mobilidades e expansões variadas, à globalização em muitas dimensões" (HANNERZ, 1997, p. 16). Em sua teoria, ele define "fluxo" como palavra-chave que aponta para uma macroantropologia, "um ponto de vista bastante abrangente da coerência (relativa) e da dinâmica de entidades sociais e territoriais maiores do que aquelas convencionalmente abordadas pela disciplina” (HANNERZ, 1997, p. 17).

\section{Deslocamentos forçados: República Democrática do Congo - Brasil}

Em “A invenção da migração" Alfredo Wagner Berno de Almeida e Moacir Palmeira apontam que o êxodo é enxergado como um processo natural, inscrito na ordem de fatos naturais e um fenômeno sempre perfilado com outros, como calamidades, mudanças climáticas, doenças, catástrofe ou crise. Essa naturalidade apresenta tais eventos como transformações bruscas que alteram o curso da vida social, se repetindo com certa frequência no desenvolvimento das sociedades, o que as tornam observáveis como cíclicas. "É justamente esta característica que ameniza sobremaneira as rupturas mencionadas, destituindo-as de qualquer sentido qualitativo pela força de uma rotinização diacrônica" (ALMEIDA e PALMEIRA, 1997. p. 37), em que estas irregularidades, por serem periódicas, são passíveis de serem reguladas, se tornando objeto de planejamentos, políticas e outras medidas de controle. 
As migrações não se apresentam de forma temporal, elas se apresentam em momentos pontuais e estão associadas a outros fatores que a constituem e provocam. Desta forma, "ser datado, ser localizado diacronicamente, é uma condição que acompanha êxodo conferindo-lhe um tempo próprio, particular" (ALMEIDA e PALMEIRA, p. 40), assinalando momentos de descontinuidade e rupturas em processos históricos contínuos e lineares. Estes eventos aludem a acontecimentos relevantes a história mundial, nacional ou local que acompanham os contornos do próprio deslocamento, não possuindo "fronteiras absolutas entre o tempo e o espaço" (ALMEIDA e PALMEIRA, p. 41). Assim, os marcadores dizem respeito ao início das condições de origem das migrações e o seu tempo é fundamentalmente representado como o tempo das rupturas em que as irregularidades se manifestam.

Ao longo de sua história, a atual República Democrática do Congo recebeu uma série de nomes. Brevemente, pode-se apontar: de 1885 a 1908 foi chamada de Estado Independente do Congo e entre 1908 e 1960 chamava-se Congo Belga. Ao conquistar a independência em 30 junho de 1960 da colonização belga, o nome novamente foi mudado e passou a se chamar República do Congo e, com o intuito de se distinguir da ex-colônia francesa também chamada de República do Congo (Congo-Brazzaville), também foi chamada de Congo-Léopoldville. Em 1964, se torna conhecida como a República Democrática do Congo, mesmo seu regime não tendo nada de democrático, e em 1971 o ditador Mobutu Sese Seeko rebatiza o país, dando-lhe o nome de República do Zaire. Este nome vigora até 1997, quando Laurent Désiré Kabila, outro ditador, retorna ao antigo nome de República Democrática do Congo. O que fica evidente, é que cada um desses nomes traz consigo um pedaço da história política do país, deixando claro momentos temporais de rupturas e descontinuidades. ${ }^{5}$

Para alguns a República Democrática do Congo é um pesadelo no paraíso, isto porque em seu território há extrema abundância de recursos naturais. Diz-se que cerca da quinta parte das reservas hídricas da terra se encontra nas terras congolesas (ZIÉGLER, 1964), metade do território é coberto de floresta e seu subsolo é extremamente rico em diversos minérios. Diante de tanta riqueza natural, o Congo tem sido visado por diversos povos com o intuito de extrair recursos e riquezas. Atualmente, as reservas de coltán tem produzido violentas invasões e guerras, permeadas ainda por embates étnicos e interesses de multinacionais. Sua

\footnotetext{
${ }^{5}$ Esta síntese tem como referência o trabalho de Kabengele Munanga: MUNANGA, Kabengele. A República Democrática do Congo. Universidade Federal de São Paulo, pág. 73 - 103.
} 
história é marcada por essas disputas e sua população vive um dos principais deslocamentos forçados do mundo.

Como exposto na teoria de Almeida e Palmeira, os deslocamentos não possuem fronteira no tempo e no espaço, no entanto, os mesmos fazem questão de complementar que há um dualismo geográfico expresso pela relação "local de saída" e "local de destino", ou seja, ela é representada como "não estando num polo nem no outro, mas como em transição de um para o outro" (ALMEIDA E PALMEIRA, 1997. p. 43). Os autores se debruçam mais especificamente a compreensão do êxodo rural, entretanto, suas reflexões também são extremamente proveitosas para uma leitura sobre a questão do refúgio. Ao "local de origem" é associada a ideia de tragédia ou calamidade, algo que provoque inevitavelmente o deslocamento. Aos aspectos geográficos, portanto, se acrescentam as realidades políticas que tornam o local de partida insustentável a determinados grupos. Os congoleses, ao chegarem ao país, apresentam inúmeros argumentos que justifiquem seu êxodo, apontando principalmente a violação de direitos humanos e perseguição. Ao "local de destino" um grande leque se abre, trazendo a imprevisibilidade de que as justificativas dos atores nem sempre são reconhecidas por instituições que representam o país, esbarrando em fronteiras que não se constituem como geográficas, mas sim políticas. Os refugiados, ao chegarem ao Brasil, precisam que seus argumentos se tornem legítimos sob a ótica das leis da nação, no qual seu discurso é testado para que eles sejam reconhecidos sob a abrangência desta categoria e tenham acesso aos direitos a eles resguardados.

\section{Breve retrospectiva histórica}

Após anos de colonização belga ${ }^{6}$, em 1960 o país se torna independente, sem nenhum processo de transição de sistemas, no qual além da incapacidade administrativa gerada pela insuficiência do sistema educacional, as divisões étnico-regionais fomentadas pelos belgas e o interesse internacional nos minérios da região resultaram em graves conflitos políticos internos. Entremeio ao caos, diversos grupos rebeldes eclodiram buscando alcançar o governo do país e resultaram em duas ditaduras: primeiro, em 1965, com o golpe militar de

\footnotetext{
${ }^{6}$ A Conferência de Berlim oficializou as terras congolesas como pertencentes ao rei da Bélgica, Leopoldo II, em 1885. Este foi um período de grande extração da região, massacrando a população local e provocando deslocamentos (que já se davam a posteriori). Em 1908, a região da atual República Democrática do Congo, tornou-se uma colônia da Bélgica.
} 
Mobutu Sese Seko, eliminando qualquer resquício de democracia; e depois, em 1996, Laurent Désiré Kabila se autoproclama presidente da república com a fuga de Mobutu.

O governo de Mobutu foi marcado por uma busca de retornar as origens africanas, extinguindo qualquer traço que remetesse a um passado colonial europeu. Em um contexto extremamente radical, em 1970 todos os partidos políticos existentes foram eliminados, criando um partido único chamado Movimento Popular da Revolução (MPR), do qual todos os cidadãos congoleses se tornaram automaticamente membros; o país foi rebatizado, assim como a moeda nacional e o rio Congo, no qual todos passaram a se chamar Zaire; cidadãos congoleses foram obrigados a abandonar os nomes ocidentais recebidos e substituí-los por nomes autenticamente africanos. Com todas essas ações, o ocidente se alinhou a esta figura para salvar seus interesses capitalistas no coração do continente africano, fato ainda mais evidenciado pelo cenário de Guerra Fria e do avanço dos movimentos socialistas nos países vizinhos.

Com a cristalização do poder em nas mãos de Mobutu, reações internas surgiram e exilados que estavam em Angola após o fim da secessão de Katanga invadem o país se rebelando contra as forças locais, contudo rapidamente são sufocados com a ajuda de tropas internacionais. Nesse contexto, os líderes oposicionistas que tentam se manifestar são presos ou mortos. Justificado pela acusação de tentativa de golpe militar, o presidente prendeu diversos generais, coronéis e oficiais. Os receios de um poder concorrente fizeram com que Mobutu progressivamente destruísse o exército que ele mesmo construiu, evento relacionado ao favorecimento étnico.

Entre 1991 e 1993, pressionado por aliados ocidentais, Mobutu iniciou um processo de abertura com uma nova legislação autorizando a volta da pluralidade partidária. Mobilizado pelo aprofundamento da crise econômica, o presidente convocou uma Conferência Nacional com a missão de solucionar o panorama econômico e preparar o país para um novo governo. Todavia, este cenário não modificou as ações autoritárias do presidente, em que nominações e demissões sucessivas ocorreram com o intuito de opor e dividir líderes do país.

Entre 1996 - 1997, Mobutu foi diagnosticado com câncer avançado e precisou se retirar do país para tratamento. Neste contexto, a Aliance dês Forces Democratiques pour La Libération Du Congo (AFDL), conduzida por Laurent Désiré Kabila, entrou pelo leste do país na fronteira com Uganda, Ruanda e Burundi, com o objetivo de libertar o Zaire da ditadura 
vigente. Sem resistência e com ínfimas manobras, as tropas de Mobutu deixaram a AFLD ocupar as cidades de Goma $^{7}$ e Bukavu, marchando em direção à capital, Kinshasa. Um encontro entre os dois líderes, Mobutu e Kabila, foi mediado por Nelson Mandela na busca pelo estabelecimento de paz.

Este período ficou conhecido como a Primeira Guerra do Congo e resultou em milhares de morte no país. Trata-se de uma guerra interestatal com formato de guerra civil entre os governos de Ruanda, Burundi, Uganda e Angola. As decisões de estabelecer a invasão ocorrem pelo colapso do regime de Mobutu e com o fim das ameças comunistas ao continente africano, acabavam as justificativas de suporte ocidental a regimes autocráticos. De acordo com Igor Castellano da Silva, os apoiadores desse projeto faziam parte de uma nova geração de líderes africanos ${ }^{8}$ e uma geração de antigos esquerdistas ${ }^{9}$. Essa percepção está alinhada à noção de que Laurent Kabila foi apenas uma peça escolhida para realizar o trabalho sujo da guerra.

A guerra foi um conflito relâmpago e em seis meses as tropas de Laurent Kabila já haviam ocupado Kinshasa. Isto se deu principalmente pela incapacidade de militar congolesa, ao amparo externo das tropas de Ruanda e Angola aos insurgentes e aos contratos de exploração de recursos naturais firmados entre Kabila e empresas ocidentais, mesmo antes de vencer a conflagração. A participação das forças externas na Primeira Guerra do Congo possibilitou que tropas dos países vizinhos já iniciassem uma prática que seria muito comum na segunda guerra do país: a expropriação de recursos naturais congoleses por tropas estrangeiras, visando o enriquecimento pessoal e nacional e o financiamento e compensações para os esforços de guerra. Quando assumiu o governo, Kabila possuía uma administração autocrática com viés autoritário, mudou o nome do país para República democrática do Congo e tomou o controle do executivo, legislativo e das forças militares

Seu governo possuía pouco apoio interno, devido a distância da população local e por se preocupar com as alianças que havia formado para conquistar o poder. Neste contexto, buscou uma abertura política projetando eleições para 1999 e instituiu reformas que podem

\footnotetext{
${ }^{7}$ Goma é uma cidade no leste da RDC, próxima a Ruanda. O Genocídio de Ruanda em 1994 se desencadeou pelo governo provisório de Ruanda controlado por elementos da etnia Hutu sobre a população Tutsi. Em resposta, movimentos rebeldes composto por refugiados Tutsi na Uganda, invadiu Ruanda, provocando um deslocamento que chegou até Goma. Esta região não só foi o abrigo de refugiados dos países vizinhos, como é uma das áreas de maior embate étnico até os dias atuais, provocando inúmeros deslocamentos forçados.

${ }^{8}$ Issayas Afeworki da Eritréia; Meles Zenawi da Etiópia; Museveni de Uganda; e Kagame de Ruanda.

${ }^{9}$ Mugabe do Zimbábue; Agostinho Neto e José Eduardo dos Santos de Angola.
} 
ser vistas como autofortalecedoras do estado reduzindo a presença estrangeira. Rompeu aliança com os Tutsis congoleses aliados a Ruanda, rescindiu o contrato de exclusividade de vendas de diamantes para empresas internacionais e, finalmente, ordenou a retirada dos oficiais burocratas ruandeses e ugandeses do país. A Segunda Guerra do Congo (também conhecida como Guerra Mundial Africana) foi o conflito decorrente da quebra da aliança vencedora da Primeira Guerra do Congo. A união Ruanda-Uganda-Burundi se refez, agora com a intenção de depor o governo que tinha ajudado a construir. A multiplicidade de países participantes na conflagração, tanto pelo lado dos agressores supracitados, quanto pelo lado do bloqueio (Congo, Zimbábue, Angola, Namíbia, Sudão, Chad e Líbia), trouxe à tona o real peso estratégico do país.

A Guerra Mundial Africana foi de 1998 a 2003. Em termos gerais Ruanda, Uganda e Burundi acusavam o governo de Kabila de não prevenir incursões de grupos rebeldes em seu território. O financiamento da guerra pelo Estado foi feito por meio de grandes concessões de exploração de recursos naturais, pois independente dos interesses iniciais dos governos estrangeiros, o custo de suas campanhas resultou na busca explícita para compensar as despesas militares. Os altos custos do conflito para ambos os lados e as pressões internacionais para o estabelecimento de cessar-fogo levaram a assinatura do Acordo de Lusaka $^{10}$ de 1999, o que proporcionou uma enorme diferença na configuração do país por não haver intervenção militar. $\mathrm{O}$ acordo previa a retirada das tropas estrangeiras, o estabelecimento de uma missão de paz da ONU (MONUC ${ }^{11}$ ) e a abertura política mediante um diálogo intercongolês. No entanto, Kabila bloqueou todos os três processos, o que irritou inimigos e aliados, resultando em seu assassinato em 2001.

Com sua morte, sobe ao governo seu filho, Joseph Kabila, com uma postura mais colaborativa, cedendo a pontos fundamentais para o cessar-fogo. Acordos entre países e grupos beligerantes, resultaram no Acordo Todo-Inclusivo de $\mathrm{Paz}^{12}$, assinado na África do Sul em 2002. O pacto consolidou a saída das tropas de Uganda e Ruanda, recuperando

\footnotetext{
${ }^{10}$ Assinado em julho de 1999, o acordo de Lusaka é ao mesmo tempo um acordo interno, internacional, político e de cessar-fogo.

${ }^{11}$ Após a assinatura do Acordo de Cessar-Fogo de Lusaka o Conselho de Segurança da ONU criou o MONUC com o objetivo de planejar a observação de cessar-fogo, retirada das forças armadas e manter contato entre todas as partes do acordo.

12 Assinado em 17 de dezembro de 2002, o Acordo Todo-Inclusivo de Paz em Predatória, no qual estabelecia a decisão final sobra a criação de um governo de transição, para existir durante dois anos, arregimentando membros de todos os grupos rebeldes.
} 
simbolicamente a integridade do Congo. No entanto, a presença de grupos beligerantes internacionais se mantém no país em busca de recursos minerais, ocupando instituições de transição e continuidade. Desta forma, a exploração ilegal se mantém e a luta entre grupos persiste, com o respaldo de grupos multinacionais.

Em 2010 o presidente anunciou o banimento da mineração e estabeleceu fiscais de comércio de exportação de mineração na região. Demais iniciativas em curso são as ações de diversas empresas internacionais do setor eletrônico, frente a pressões de ONG internacionais, em direção a maior transparência em seus canais de fornecimento. Com este novo panorama, houve uma "sensibilização" da economia internacional, tendo em vista os "bons" esforços do novo presidente em integrar o país a política internacional. Isto resultou na colaboração do Fundo Monetário Internacional (FMI) e do Banco Mundial para com o perdão da dívida externa.

Somado a todos os intermitentes relatados sobre a história da República Democrática do Congo, acionados por conflitos étnicos internos e intervenções políticas e de segurança externas, há a busca incansável pelos recursos minerais da região, em especial, o coltán. O cruzamento destas realidades tem causado uma grave situação humanitária, que é impulsionado pelo mercado de empresas multinacionais através da exploração ilegal do minério, fornecendo fundos para grupos a margem da lei, continuando a guerra e empobrecendo o Estado, privando-o de oportunidades econômicas para suprir as necessidades básicas da população. A luta pelo controle das zonas mineiras ainda se dá entre grupos de Ruanda, Uganda e RDC, que o comercializam nos mercados internacionais de forma ilegal, implicando em trabalho forçado, extorsão e violência.

A importância do coltán reside em seu material ser extremamente resistente e refratário, suportando temperaturas excepcionalmente altas, tornando-o uma excelente matéria prima para o desenvolvimento de tecnologias modernas. Na RDC a exploração do coltán está totalmente ligada não apenas a guerra e conflitos de grupos armados, mas concomitantemente a situações de semiescravidão, exploração infantil, desastres ambientais gravíssimos e problemas de saúde que assolam de forma generalizada a população local. Os grandes riscos que a população corre pela extração deste mineral é pago de forma proporcionalmente inversa, no qual o preço do coltán chega a ser irrisório. 


\section{Deslocamentos congoleses}

Esta seção tem como base três pontos de reflexão. Dois constituem-se em referências bibliografias que perpassaram narrativas e relatos de refugiados, com o intuito de compreender os motivos de deslocamento, as formas como são feitas e os mecanismo que creditam a sua condição de refugiado. Compõe esta análise, minha experiência de campo em que, ao dar aula de português para refugiados congoleses, pude ouvir breve relatos, ler textos e ouvir histórias. A esta ferramenta não pude dispor de grande aprofundamento, tendo em vista que ao me tornar voluntária da Cáritas Rio e ACNUR me comprometi a não realizar perguntas pessoais, mas sim encaminhar imediatamente a agentes da instituição quando algo particular chegasse ao meu alcance. Este esforço ajuda a compor um quadro que justifique o investimento que uma rede instituições vem fazendo para ajudar pessoas em situações de deslocamento forçado, onde diversos campos do desenvolvimento constroem canais para atuar sobre este fenômeno.

Em fevereiro de 2009, autoridades nacionais e internacionais anunciavam o fim da guerra no leste da RDC, através da aliança realizada com líderes de Ruanda. No entanto, notícias recentes relatam que os civis continuam a sofrer com conflitos no país nas regiões de Kivu Norte e Kivu Sul e há pontos controversos sobre a aliança formada entre os dois países para a captura de Laurent $\mathrm{Nkunda}^{13}$, com fatores obscuros a respeito dos resultados dessa operação. O movimento crescente nas solicitações de refúgio no Brasil reflete o conturbado contexto das eleições presidenciais de 2006, a contestação dos resultados pelos opositores de Joseph Kabila, os embates e conflitos ocorridos logo após as eleições entre os partidários de J. Kabila e de Jean Pierre Bemba, além do aumento das perseguições e pressões de

\footnotetext{
13 "Nkunda é o líder de um grupo de rebeldes que vem lutando contra o exército congolês e outras milííias desde 1998. Ele é nativo de Norte Kivu, no Congo oriental. Nkunda professa ser um protetor e libertador dos Tutsis, sua etnia, perseguida por Hutus ruandeses que cruzaram a fronteira no Congo depois do genocídio da segunda metade dos anos 90. Em 2003, o governo congolês esboçou um acordo com os rebeldes, onde milícias se uniriam ao exército nacional. Foi oferecido a Nkunda o posto de general, mas ele preferiu fugir e tem lutado desde então para o desarmamento dos Hutus ruandeses e milícias no Congo oriental. Apesar de várias tentativas de cessar fogo, acordos de paz e negociações entre o grupo dele e o governo de Joseph Kabila, Nkunda recusou todos: não se rendeu desde que formou sua facção rebelde em 2004. Foram deslocadas de um a dois milhões de pessoas desde 2007 na região oriental de Congo RDC. Em outubro de 2008, o CNPD, liderado por Nkunda, intensificou sua ação no Kivu Norte e algo entre 100.000 a 200.000 pessoas foram expulsas de suas casas. Agências de ajuda humanitária e outros críticos classificam Nkunda como um poderoso "senhor da guerra" cujas tropas aterrorizaram e violentaram civis em uma tentativa de controlar uma parte do Congo, onde a terra é rica e depósito de minerais valiosos. A organização Human Rights Watch pediu reforços ao governo congolês para capturar Nkunda e processá-lo por crimes de guerra". Fonte: Tannuri, Maria Regina Petrus. Refugiados congoleses no Rio de Janeiro e dinâmicas de "integração local" :2010.
} 
colaboradores do candidato derrotado. De acordo com os estudos de Maria Regina Petrus Tannuri, em que esta recolhe informações a partir do ACNUR, Cáritas Rio, depoimentos de refugiados e matérias de jornais, a província-capital Kinshasa, a região dos Kivu Norte e Sul e a província do Bas-Congo são apontadas como as áreas de origem da maior parte dos congoleses que chegam ao Rio de Janeiro.

$\mathrm{Na}$ tese de Tannuri há a exposição de relatos que mapeiam os deslocamentos dos refugiados congoleses, expondo o percurso que estes realizam para chegar ao Brasil e os motivos pelos quais saíram de seu país de origem. $\mathrm{Na}$ análise dos relatos, fica claro que o primeiro movimento ocorre através do cruzamento de fronteiras com países vizinhos, buscando fuga imediata de situações de perseguição devido ao contexto político-religioso da RDC. Essas fugas ocorrem com o auxílio financeiro e estratégico de grupos políticos aos quais os atores fazem parte, em que a África do Sul se apresenta como um território seguro até que deslocamentos mais distantes possam ser feitos. O Congo-Brazzaville também se apresenta como uma possibilidade de deslocamento inicial, mas não possui a mesma segurança. As fugas parecem ser realizadas primeiro pelo indivíduo que está sofrendo perseguições e depois, quando possível, sua família, se estabelecendo no Brasil, buscando ser reconhecido enquanto refugiado e à procura de conseguir documentos para que possam trabalhar.

Durante minhas aulas de português para refugiadas na Cáritas Rio, o tema "trabalho" foi o de maior demanda pelos alunos. Após a conquista dos documentos, há uma ansiedade em conseguir um emprego que pode ser justificada pelo contexto social que estamos inseridos, mas também por representar uma "nova" vida para os refugiados, onde após a ruptura há o estabelecimento: a "pessoa que chega hoje e fica amanhã" (SIMMEL, 1908. p. 182). Ficar é algo de extrema importância para os refugiados e em muitas conversas antes do início das aulas eles pediam ajuda com currículo, anúncios e cartas de apresentação. Como retrata Simmel (1908, p. 188), o estrangeiro não está organicamente anexado ao grupo, mas é um membro orgânico do mesmo na medida em que sua vida inclui condições comuns da sociedade, como a busca por emprego, moradia, educação, saúde, etc.

Os motivos de deslocamento forçado estão totalmente atrelados ao contexto histórico do país, aos fluxos econômicos e políticas globais. É evidenciado as guerras entre etnias que são financiadas por interesses externos na busca por minérios, em especial o coltán. É 
alardeado pela mídia os conflitos entre os hutus e tutsis, mas muitos refugiados expõem que mais do que questões étnicas, os enfrentamento se dão pela busca por domínio de territórios e questões políticas. Grupos opositores ao governo vigente são perseguidos e acusam o mesmo de realizar torturas, o que produz a necessidade de buscar amparo em outro local. Finalmente, outro motivo apontado são as divergências religiosas também pautadas em política, em especial na região de Bas-Congo.

O deslocamento da RDC até o Brasil percorre diferentes pontos do continente africano. Os primeiros deslocamentos se dão por vias terrestres entre um país e outro mesmo que eles não façam fronteira, como a África do Sul - ou entre uma região e outra. No continente africano este percurso pode ser realizado de duas formas, avião ou navio. Quase não ouvi ou li - nos trabalhos feitos em sala - histórias que retratassem as formas de deslocamentos dos congoleses para o Brasil e fui aconselhada pelos agentes da Cáritas Rio a não perguntar sobre isso, pois são histórias fortes que podem trazer desconforto aos refugiados. Quando eles contavam sua história, falavam de como era a vida na RDC, onde viviam, o que comiam e o que faziam profissionalmente; quase nunca falavam de seu envolvimento com política ou questões étnicas - e estas também não pareciam existir em sala de aula - e muito menos do percurso que realizaram para chegar ao país. Em sua retrospectiva havia o momento que estavam lá e, finalmente, o que estavam aqui, a interconexão entre estes dois pontos não era relatada.

\section{Canais institucionais de apoio ao refúgio no Brasil - Rio de Janeiro}

São muitos os canais que se formam para atuar sobre a causa dos refugiados no mundo e diversas instituições ${ }^{14}$ se relacionam em busca de remediar os impactos desse fenômeno na vida dos sujeitos. Ao mesmo tempo, são essas instituições que estabelecem classificações e procedimentos para enquadrá-los nesta categoria. Esta esfera se coloca no campo do desenvolvimento por envolver múltiplas frações de populações locais, empresas privadas, corporações nacionais, internacionais e transnacionais. A teoria do "campo", de acordo com Bourdieu (1983), é construída a partir de generalizações que vão sendo pouco a pouco efetuadas, em que ao empreender o estudo de um campo particular descobre-se características

\footnotetext{
${ }^{14}$ Dentre elas compreende-se organizações governamentais, organizações não-governamentais, igrejas, sindicatos, agências multilaterais, entidades industriais e corporações financeiras.
} 
que lhe são específicas, mas que podem, ao mesmo tempo, auxiliar na análise de outros campos. Estes resultam de processos de diferenciação social e o que lhes dá suporte são as relações de força entre os agentes e as instituições que lutam pela hegemonia, ou seja, o monopólio da autoridade, que concede o poder de ditar as regras e de repartir o capital específico de cada campo (BOURDIEU, 1983). Cada campo de desenvolvimento possui estruturas e dinâmicas próprias, ligadas as suas capacidades de poder e interesse articuladas através de processos históricos e de estruturação de redes.

De acordo com Ribeiro (2008) ““desenvolvimento’ abarca diferentes visões e posições políticas variando do interesse em acumulação de poder econômico e político a uma ênfase em redistribuição e igualdade". O campo do desenvolvimento é constituído por lutas entre atores e instituições, no qual pontos diferenciados de poder resultam numa rede de relações que expressam a estratificação desta esfera, no qual emergem desde grandes instituições financiadoras - que pautam determinadas ações - e pequenas ONGs - que em muitos momentos realizam ações na microesfera. $\mathrm{O}$ autor ressalta que os atores e instituições mais poderosas deste domínio se empenham na reprodução do campo como um todo, já que seus interesses estão intimamente ligados a tal existência.

Pertencente ao campo do desenvolvimento, uma das áreas de atuação da ajuda humanitária se estabelece sob o respaldo aos refugiados. Em minhas investigações, busquei traçar as veias deste organismo a partir da atuação da Cáritas Arquidiocesana do Rio de Janeiro, que se apresenta como principal entidade representante da sociedade civil neste setor. Ressalto que nesse momento apresentarei os canais institucionais burocraticamente estabelecidos pela instituição em documentos, mas friso que na prática estes canais se tornam emaranhados de difícil visibilidade por não se apresentarem da forma como é descrita e se estenderem a outras entidades parceiras não mencionadas. Somente através do campo pude perceber as sutilezas que se estabelecem em parcerias e correspondências, quando nem sempre aquilo que se apresenta como óbvio é factível. Este fenômeno não ocorre por um interesse em obliterar determinadas informações, mas pelas relações se constituírem de forma orgânica de difícil correspondência com as hierarquias burocraticamente impostas.

Para compreender a atuação da Cáritas Arquidiocesana do Rio de Janeiro, é preciso entender que esta é uma pequena vertente que compõe um quadro muito maior da instituição. A rede Cáritas é extremamente grande e atua em mais de 200 territórios do globo de 
diferentes formas. Sua central é a Cáritas Internationalis e é tida como o braço social da Igreja Católica, onde desta matriz descende seus derivados que atuam de forma plural dentro da ajuda humanitária. No Brasil, a entidade central é a Cáritas Brasileira, fundada em 1956, e possui 183 entidades-membros em todo o território nacional, atuando de formas variadas. A capilaridade desta rede é imensa e abrange diversas iniciativas, como fomento a economia solidária, segurança alimentar e nutricional, trabalho com jovens, mulheres, catadores de materiais recicláveis, pequenos agricultores, acampados e assentados da reforma agrária, populações tradicionais e movimentos sociais. Com amplo leque de atuação, a rede Cáritas propõe certa autonomia as entidades-membros criando subdivisões de correspondências ${ }^{15}$, liberdade para busca de recursos, associação com entidades parceiras e métodos de atuação.

A "independência" das entidades-membros possibilita a formação de muitos outros canais, pois cada uma delas se relaciona com diferentes instituições, de acordo com sua temática e territorialidade. A rede Cáritas está inserida em diversos campos da filantropia, suas nuances perpassam o combate à pobreza, fome, auxílio ao campo, entre outros, onde cada temática desta envolve diferentes atores e agências e cada uma se relaciona com as vertentes que se aproximam do seu campo de possibilidades. A Cáritas Arquidiocesana do Rio de Janeiro trabalha com refugiados e as instituições que se juntam a ela tem interesse nesta abordagem, diferente de instituições que se associam com a Cáritas Arquidiocesana de Montes Claros, por exemplo, que trabalha com agricultores do semiárido e tem grande proximidade com movimentos sociais da região. Desta forma, cada uma cria sua própria rede, se articulando com instituições que se aproximem do seu tema e interajam localmente.

Ao perceber estes dois níveis de intercâmbio entre as diversas entidades que compõem a rede Cáritas, global e local, é possível fazer uma sensível aproximação ao estudo de Arjun Appadurai (1986) “A vida social das coisas”. Embora seu empreendimento esteja voltado para objetos, sua reflexão também se debruça sobre as relações que se tecem a partir do valor que as trocas constituem. Quando sua reflexão recai sobre os estudos do kula de Malinowski, é possível fazer uma aproximação de como os trânsitos de dádivas e reciprocidades se aproximam das redes de desenvolvimento e filantropia. Segundo o autor, o termo keda é usado para descrever o percurso que os objetos fazem de uma ilha a outra e agrega a isto

\footnotetext{
${ }^{15}$ A instituição se articula nacionalmente em três níveis: Cáritas Diocesanas, Secretariado Regional e Secretariado Nacional.
} 
significados de vínculo social, político e reciprocidade entre os homens que fazem parte desta rota, relacionando-se à riqueza, ao poder e à reputação dos homens que negociam entre si.

A rede Cáritas é composta por diversas rotas e intercâmbios que produzem valor e estabelecem vínculos institucionais e pessoais. A autonomia prevista nesta esfera requer um comprometimento das entidades em estabelecerem mecanismos que a mantenham conectadas, onde mesmo estando espacialmente distantes e com abordagens diferentes possam apresentar uma unidade em si. É o compromisso em produzir rotas - fluxos de informação, decisão e parceria - que produz mecanismos de funcionalidade e permitem a amplitude desta instituição, transacionando valores, conhecimentos e métodos que podem ser compreendidos sob a ótica do valor.

Como supracitado, a Cáritas Arquidiocesana do Rio de Janeiro atende a refugiados e sua rede de articulação institucional gira em torno desta temática. Seguindo as informações disponíveis em documentos da instituição, são duas as principais instituições que constituem esta rede: o Alto Comissário das Nações Unidas (ACNUR) e o Comitê Nacional para os Refugiados (CONARE). O ACNUR foi criado em 1950 com o objetivo de reassentar refugiados europeus após a Segunda Guerra Mundial; atualmente, sua função é dirigir e coordenar a ação internacional para proteger e ajudar as pessoas deslocadas em todo o mundo e encontrar soluções duradouras para elas. Esta agência possui forte relação hierárquica com a Cáritas Rio, de forma que é a ela quem a instituição se reporta e de onde provem parte de sua receita, além de utilizar os termos e condições da ONU. Com o objetivo de reconhecer e tomar decisões sobre a condição de refugiado no Brasil, o CONARE é um órgão multiministerial do qual participam o governo, a sociedade civil e a ONU, via ACNUR. É ele responsável por definir quem pode ser reconhecido como refugiado ou não e concede documentos. A Cáritas Rio busca auxiliar os refugiados no processo de elegibilidade do CONARE, assessorando com advocacia, reconhecimento de fatos e contexto histórico do país, oferecendo respaldo e acompanhamento.

Ainda em mente as análises de Appadurai sobre o kula, o autor evidencia que as trocas não se dão apenas nas fronteiras entre as comunidades, mas também se realizam trocas mais próximas. $\mathrm{O}$ autor expõe o termo kitoum para designar a articulação entre o kula e outras modalidades de troca, em que há "cruciais vínculos conceituais e instrumentais entre as rotas mais curtas e mais longas que formam a totalidade do mundo das trocas em Massim" 
(APPADURAI, 1986. p. 35). O mesmo acontece com as redes institucionais da Cáritas Rio, que se relacionam de diferentes formas e intensidades com outras instituições, conectando-se as mais distantes, como o ACNUR e a Cáritas Internationalis, àquelas que são localizadas nacionalmente, como a Cáritas Brasileira e o CONARE, e as instituições locais, entidades que se propõem auxiliar o atendimento a refugiados. Essa diversidade compõe um quadro com fluxos de diferentes rotas por compor diferentes relações, no qual algumas pautam-se em hierarquias e burocracias, outras estão conjecturadas no âmbito da parceria.

É este fluxograma que busco compreender, de forma a dar sentido ao quadro de dádivas que evoca a ajuda humanitária a refugiados, abrangendo trocas voluntárias e obrigatórias, interessadas e desinteressadas, úteis e simbólicas (MAUSS, 1974. p. 14) entre os atores envolvidos. Sob o amplo espectro da atuação da Cáritas no Brasil, reflito as redes que se formam para atuar com determinada temática e região e como isto contrasta com outras dioceses que produzem redes totalmente diferentes. Por estar inserido no campo do desenvolvimento, estas relações precisam ser aprofundadas, saindo da superficialidade que pode evocar o termo "ajuda" e adentrar nos interesses inseridos em suas ações. Nestas relações há uma gramática instituída, que é produzida e reproduzida por diversos agentes da filantropia e regulariza burocraticamente os mecanismos e formas de atuação.

\section{O encontro dos dois pontos: chegada ao Brasil e desdobramentos}

Neste momento, após expor os motivos de migração forçada dos refugiados congoleses para o Brasil e os aparatos institucionais que se encarregam de auxiliá-los, busco expor situações de confluência destes dois pontos e os desdobramentos práticos que ocorrem deste encontro. Para chegar a este momento, dois tipos de fluxos puderam ser observados: primeiro, a circulação de pessoas que atravessam fronteiras em quantidade cada vez mais crescente; e, a circulação de informação, conhecimento e valor, através da conexão de diversas instituições bilaterais. Ainda que possuam rotas diferentes, sejam movidos por diferentes atores e se estabeleçam de formas variadas, o encontro destes dois é produzido na realidade e sobre um determinado fenômeno, seus desdobramentos criam novas informações, dados e metodologias para lidar com situações de refúgio e acolhimento.

Embora os números cada vez mais indiquem um movimento de massa entre os congoleses, há outros movimentos que ressaltam o significado individual de fugas. Seja por 
motivações humanitárias, reencontro de familiares, ordem de segurança nacional, entre outros, o Estado brasileiro se preocupa em classificar cada história a fim de enquadrá-la na categoria de migrante ou refugiado. Segundo Aryadne Bittencourt, é por temer a entrada de grandes grupos de migrantes que o governo brasileiro tem justificado a necessidade de avaliar individualmente cada pedido de refúgio. $O$ processo de elegibilidade ${ }^{16}$ entende que apenas será concedida documentação formal de permanência no Brasil àquele indivíduo que for realmente refugiado, categoria esta que não se enquadra nos processos de autodefinição, pois não basta os indivíduos declararem terem fundadas razões para não quererem ou não poderem voltar para seu país de naturalidade. "A condição de refúgio é construída pelo próprio Estado e validada por ele. Isto quer dizer que o CONARE seleciona individualmente as histórias de vidas narradas, classificando-as de acordo com indícios de verdade" (BITTENCOURT, 2016. p. 78). As narrativas sobre os refugiados são moralizadas e os colocam na condição de vítimas, os solicitantes de refúgio precisam se apresentar fora das zonas de dúvidas para serem aceitos, em que para se adequarem a este regime os refugiados precisam "se desfazer dessas ambiguidades, contradições, dúvidas e esquecimentos que costumam caracterizar as experiências vitais das pessoas" (VIANNA e FACUNDO, 2015). De acordo com os critérios de elegibilidades, o reconhecimento do indivíduo como refugiado traz hierarquias políticas e morais entre os refugiados e os eventuais outros grupos de migrantes.

Para se enquadrar como solicitante de refúgio, as pessoas em situação de deslocamento passam pelos procedimentos da Polícia Federal em que é emitido um protocolo que os enquadre formalmente nesta categoria. Após este procedimento, é resguardado o direito de estada regular no país até decisão definitiva do processo e o acesso a documentos, como CPF e carteira de trabalho. Com este protocolo, os solicitantes de refúgio chegam a Cáritas Arquidiocesana do Rio de Janeiro e são inseridos na dinâmica de atendimento da instituição, realizando entrevistas, encaminhados para programas de acolhimento - como curso de português - e respaldo jurídico para seu processo.

É neste ponto que ambos os fluxos colidem, cada um carregado de imensas redes, relações e histórias, perpassando diferentes pontos do mapa para enfim convergir em um processo de elegibilidade. Duas entrevistas são realizadas quando os sujeitos chegam a

\footnotetext{
${ }^{16}$ Conjunto de procedimentos para que um solicitante de refúgio seja reconhecido institucionalmente por um Estado na categoria jurídica de refugiado.
} 
instituição: uma de teor social, junto às assistentes sociais, e outra de elegibilidade, feita por advogados, para compor os processos de refúgio do caso e conhecer mais a fundo história do solicitante, vislumbrando potenciais oportunidades de proteção legal. Como a Cáritas Arquidiocesana do Rio de Janeiro possui representação no CONARE, um conhecimento mais consistente dos casos permite melhor atuação nas discussões e disputas sobre deferimento e indeferimento dos pedidos. As perguntas da entrevista são basicamente sobre a história de vida antes da fuga, as razões da fuga e o trajeto percorrido na fuga até chegar ao Brasil.

As entrevistas levam tempo para ocorrer e não adotam um sentido cronológico (por ordem de pedidos), vigorando sob postulados internos do CONARE. Este órgão é responsável por analisar o pedido e decidir sobre o reconhecimento da condição do refugiado, em que a decisão é colegiada. De acordo com Bittencourt (2016) a construção do posicionamento oficial geralmente não se dá por votos dos membros, mas por discussões e acordos, de forma que a decisão seja consensual e que os membros que não possuem direito a voto - ACNUR, $\mathrm{DPU}^{17}, \mathrm{e} \mathrm{IMDH}^{18}$ - tenham a oportunidade de participar ativamente do processo.

O funcionamento do CONARE e as ações do ACNUR no Brasil frente aos solicitantes de refúgio e refugiados, traz a necessidade de normatização destas populações com o intuito de perfilá-las a nação. Com o estudo "Anthropology in the Margins of the State" (2004) de Veena Das e Deborah Poole é possível refletir como políticas públicas em áreas específicas moldam práticas políticas, regulatórias e disciplinatórias. A ideia central das autoras é repensar a fronteira entre o centro e a periferia, público e privado, legal e ilegal, questionando a ideia difundida de que as margens espaciais e sociais de um Estado são lugares de desordem.

Ao aproximar o caso de refugiados das análises de margens das autoras e da compreensão do Estado como um órgão imbuído de capacidade de ordenação, é possível perceber o engajamento do mesmo nas ações do CONARE e o esforço em "pacificar" exceções, em analisar caso a caso aqueles passíveis de elegibilidade e aqueles que estão fora deste escopo. A exceção fortalece a regra, no sentido de que localiza aquele que possui o poder de dar veracidade e normatizar sujeitos, inserindo-os na sociedade em que chegam. A população de refugiados, em muitos momentos, é tratada de forma homogênea, em especial

\footnotetext{
${ }^{17}$ Defensoria Pública da União

${ }^{18}$ Instituto de Migrações e Direitos Humanos
} 
quando os recortes recaem sobre Estados-nações e dados estatísticos que buscar fotografar fluxos contínuos. O processo comparativo dos relatos individuais com os contextos históricos nacionais e fluxos migratórios, observa estas populações como entidades homogêneas que carecem de regulamentação para serem inseridas ao contexto brasileiro - distanciando-se dos fatores individuais inerentes aos seres humanos que podem motivar o deslocamento.

\section{Apontamentos}

A reflexão sobre este exercício remonta questões a respeito do campo do desenvolvimento e aos derivados que este tema abarca ou, no mínimo, contorna. A ajuda humanitária recai, principalmente, sobre a sensibilização da dor do "outro", evocando o engajamento de pessoas e instituições na melhoria da vida humana. Esta perspectiva, inevitavelmente, perpassa por concepções globalizadas de direitos humanos que clamam por estados de respeito e igualdade. A situação dos refugiados se conecta a esta rede de conceitos e conhecimentos, onde uma série de entidades pautadas no que é reconhecido como direitos humanos universais rompem fronteiras com o intuito de atuar sobre esta realidade, mobilizando inúmeros atores local e globalmente. Neste sentido, por vezes, se torna difícil compreender onde se enraízam determinadas gramáticas e metodologias e quais são as justificativas que pulsam nestes empreendimentos.

Em busca de apontar a aplicabilidade de leis em espectro planetário e lançar luz sobre a abrangência dos direitos humanos e suas origens, Bryant Garth (2008) mostra como cada vez mais esta temática vem ganhando espaço nas relações transnacionais, em especial nas interações entre Estados-nações. Este cenário se constitui ao longo da Guerra Fria, em que Estados Unidos e União Soviética disputavam pelos parâmetros de ideologia e aplicabilidade de políticas voltadas para a sociedade, utilizando destes argumentos para conquistar entrada em outros países e territórios, com o auxílio de agências multilaterais - o exemplo utilizado pelo autor é a entrada dos Estados Unidos no Chile com a queda de Allende e ascensão de Pinochet. Como ele aponta,

The growing legitimacy of this approach helped put Amnesty and others who had increased their investment in human rights ideals into a position take advantage of a series of events and crises that occurred in the late1960s and early 1970s. These events related to a relative decline in cold war pressures as well. (GARTH, 2008. p. 259) 
Uma série de empresas, grupos e ONGs passaram a se pautar nestes ideais, em especial com países em desenvolvimento, difundindo este conhecimento e exercitando aquilo que Foucault reconhece como governamentalidade, no qual ele define como:

\begin{abstract}
"o conjunto constituído pelas instituições, procedimentos, análises e reflexões, os cálculos e as táticas que permitem exercer essa forma bem específica, ainda que complexa, de poder que tem por alvo principal a população, por forma maior de saber a economia política, por instrumento técnico essencial os dispositivos de segurança. Segundo, por 'governamentalidade' entendo a tendência, a linha de força que, em todo o Ocidente, não cessou de conduzir, e desde muito tempo, à preeminência desse tipo de poder que podemos chamar de 'governo' sobre todos os outros: soberania, disciplina, e que, por uma parte, levou ao desenvolvimento de toda uma série de aparelhos específicos de governo [e, de outra parte], ao desenvolvimento de toda uma série de saberes. (FOUCAULT, 2008, p. 143 - 144)
\end{abstract}

Esta reflexão é bastante proveitosa quando recai sobre o panorama atual de deslocamentos forçados e grandes fluxos que vem se estabelecendo para atuar sobre esta realidade. Os postulados de conhecimento transnacional a respeito de violações aos direitos humanos é pauta decisiva para reconhecer a um indivíduo a condição de refugiado, inferindo uma legislação global que atua de diversas formas em diferentes países, através de redes de instituições, agências internacionais ou leis, como a rede Cáritas e o ACNUR. A presença e relação destas entidades no Brasil infringe mecanismos de interpretação e atuação para pessoas em situação de refúgio que se baseiam em códigos universais e estabelecem formas de governamentalidade no país.

Deslocar o poder do aparato estatal e observar que outras instâncias também possuem a faculdade de classificar e nomear, estratificando populações, territórios e saberes, possibilita compreender práticas e conceitos que fundamentam noções de como uma sociedade deve ser e aquilo a que ela deve aspirar, construindo uma visão de mundo. Ao consolidar esse espectro de governamentalidade, elas se tornam cada vez mais naturais e absorvidas pela sociedade, o que possibilita compreender a nomeação de fenômenos e eventos que recebem interpretações específicas quando estão sob o pilar mais amplo da cooperação internacional, como o caso do refúgio. A produção do conceito de refugiado tem sido um "processo dinâmico marcado pelo pragmatismo, na tentativa de responder, em geral a posteriori, as crises humanitárias já instaladas e fluxos de refugiados já em marcha" (SILVA, 2012. p, 15), ou seja, a circulação de 
pessoas é algo que se dá antes mesmo destes eventos terem nome. Com isto em mente, compreende-se que a mobilização de instituições tem como objetivo responder a processos anteriores, ampliados em determinados momentos (como atualmente) e estabelecer normas e procedimentos para atender esta demanda. No entanto, estes próprios mecanismos se tornam ferramentas para a construção do fenômeno, que se antes não tinha nome, agora possui também dados, estatísticas, órgãos responsáveis e leis. 


\section{Referências Bibliográficas}

ALMEIDA, Alfredo Wagner e PALMEIRA, Moacir G.S.. A invenção da migração. In: Relatório Final do Projeto Emprego e Mudança Sócio-econômica no Nordeste: vol. 1. Rio de Janeiro: PPGAS-MN/UFRJ. (Manuscrito), 1977.

APPADURAI, Arjun. Introduction: Commodities and the Politics of Value. In: The Social Life of Things: Commodities in Cultural Perspective. Cambridge: Cambridge University Press. Pp. 3-63, 1986.

BOURDIEU, Pierre. Esboço de uma teoria da prática. In: ORTIZ, Renato (org). A sociologia de Pierre Bourdieu. São Paulo, Ática, pp.39 - 81, 1983.

O espaço social e suas transformações. In: A distinção - crítica social do julgamento. Porto Alegre, Zouk, pp. 95 - 160, 2007.

DAS, Veena e POOLE, Deborah. Anthropology in the Margins of the State. Santa Fé, Oxford: School of American Research Press/ James Currey, 2004.

FOUCAULT, Michel. Governmentality. In: SHARMA, Aradhana e GUPTA, Akhil (eds.). The anthropology of the state: a reader. Oxford: Balckwell Publishing, p. 131-143, 2006.

GARTH, Bryant G.. The Globalization of the Law. In: WHITTINGTON, Keith E., KELEMEN, R. Daniel \& CALDEIRA, Gregory A. (eds). The Oxford Handbook of Law and Politics. Oxford: Oxford University Press. Pp. 245-264, 2008.

HANNERZ, Ulf. Fluxos, fronteiras, híbridos: palavras-chave da antropologia transnacional. In: Mana, 3(1): pp. 7-39, 1997.

MAUSS, Marcel. Ensaio sobre a dádiva. Forma e razão da troca nas sociedades arcaicas. In: Sociologia e Antropologia. v. II. São Paulo: Edusp, 1974.

MUNANGA, Kabengele. A República Democrática do Congo. In: Conferência Nacional de Política Externa e Política Internacional - II CNPEPI: o Brasil no mundo que vem aí.

Seminário: África — Brasília. Fundação Alexandre de Gusmão, 2008.

Conflitos, Traumas e Memórias. Texto da conferência para alunos de história da Universidade do Estado de Santa Catarina (UDESC) - 04 de outubro de 2013. Revista da ABPN・v. 5, n. $11 \cdot$ jul.- out. $2013 \cdot$ p. 220-234

RIBEIRO, Gustavo Lins. Poder, redes e ideologia no campo do desenvolvimento. In: Novos estudos - CEBRAP [online], n.80, pp.109-125, 2008.

SILVA, César Augusto S. da. Direitos Humanos e Refugiados. Ed. UFGD, 2012.

SIMMEL, Georg. O estrangeiro. In RBSE 4(12): 265-271, 2005. 
TANNURI, Maria Regina Petrus. Refugiados congoleses no Rio de Janeiro e dinâmicas de "integração local": das ações institucionais e políticas públicas aos recursos relacionais das redes sociais. Tese de Doutorado. Rio de Janeiro: Programa de Pós-graduação em Planejamento Urbano e Regional da Universidade Federal do Rio de Janeiro (UFRJ), 2010.

VIANNA, Anna Catarina Morawska. Os Enleios da Tarrafa: etnografia de uma parceria transnacional entre ONGs através de emaranhados institucionais de combate à pobreza. Tese de Doutorado. São Paulo: Programa de Pós-graduação em Antropologia Social da Universidade de São Paulo (USP), 2011.

WALDELY, Aryadne Bittencourt. Narrativas da "vida em fuga": a construção políticojurídica da condição de refugiado no Brasil. Dissertação de mestrado. Rio de Janeiro: Programa de Pós-graduação em Direito da Universidade Federal do Rio de Janeiro (UFRJ), 2016.

Recebido em: Maio de 2018

Aprovado em: Julho de 2018 